\title{
Modelling of thermal and stress-strain state of transformable space structures from hybrid composite materials
}

\author{
Konstanitin Mikhaylovskiy ${ }^{1, *}$, and Pavel Prosuntsov ${ }^{1}$ \\ ${ }^{1}$ Bauman Moscow State Technical University, 105005 Moscow, Russia
}

\begin{abstract}
The strikes of the meteoroids represent a serious danger for transformable space structures. Multilayer plates and shells made of hybrid composite materials can be effectively used for protection and thermal control of such structures. The results of the analysis of the thermal regime and shock resistance of a multilayer structure flying in a circular orbit 400 $\mathrm{km}$ high are presented.
\end{abstract}

\section{Introduction}

Prospective exploration of the near-Earth space and the Solar System is associated with large-scale orbital and planetary structures with advanced shells made from hybrid composite materials. The basic concept of the TransHab (Transit Habitat) inflatable space modules was developed in the 1990s by NASA [1-4]. They proposed the following combination of layers: the atomic oxygen protective layer, the thermal protection system, the micrometeoroid/ orbital debris shield, the seal interface, the restraint layer, the triply redundant bladder system, and the inner layer. In 2016, the Bigelow Expandable Activity Module (BEAM) was successfully docked to the International Space Station (ISS) for full-scale tests [2]. In Russia, RSC Energia has created a prototype of an inhabited module with a multilayer transformable shell $[5,6]$. Expandable space structures from composites can also be used in small spacecraft designed to capture and deorbit space debris $[7,8]$.

One of the key problems in creating expandable structures with multilayer elements is the selection and justification of the materials and the layer thicknesses with regard to the operating conditions in space, including impacts of meteoroids and space debris.

\section{Statement of the task and the method modelling}

The object of investigation is a space debris catcher (Fig. 1) and a shell of a prospective ISS module. It is assumed that the catcher flaps and the module shell have identical multilayer structure. Layer 1 (top) comprised the $10 \mathrm{~mm}$ thick screen vacuum thermal insulation (EVTI-I type) coated with the metallized arimid fabric (product identification number 5397-92). The screen vacuum shield is composed of several 20-micron polyimide film

\footnotetext{
*Corresponding author: kosmiv@yandex.ru
} 
layers separated by a fiberglass scrim. Layer 2, a part of the meteoroid protective system, was a 15-layer fabric stack. The fabric (product identification number 8601) has the following properties: $190 \mathrm{~g} / \mathrm{m}^{2}$ linear density, plain weave, 15 warp threads by $15 \mathrm{weft}$ threads, 58 tex. Layer 3 was the $40 \mathrm{~mm}$ screen vacuum shield. Layer 4 was a 20-layer arimid metallized fabric stack, with $4 \mathrm{~mm}$ total thickness.

The thermal state modeling did not take into account the possibility of the screen vacuum shield compacting under load, the presence of elastic shell deployment elements, which may act as "thermal bridges", as well as the power and sealing shell layers with low thermal resistance due to their small thickness $(0.5$ to $1.0 \mathrm{~mm})$. Both layers of the screen vacuum shield and both layers of the meteoroid protection were considered as a continuous material without internal microstructure. The thermal physical and physical mechanical characteristics of the materials were assumed to be temperature-independent.

For the stress-strain modeling, the following assumptions were introduced:

- interaction on the shell boundary layers, as well as with the spacecraft elements is carried out with the help of surface-to-surface contact finite elements, with friction between layers accounted for; inner degrees of freedom of the shell layers are disregarded;

- the layers of the screen vacuum shield and the arimid metallized fabric (8601) were regarded as 3D orthotropic materials. Large deformations and displacements in the materials, including quasi-plastic ones, were also taken into account. In addition, the heating and heat propagation effects under high-velocity impact were evaluated. For stress analysis, the maximum stress failure criterion was used (temperature-dependent). It was taken into consideration that the arimid fabric stack consists of $0.22 \mathrm{~mm}$ thick layers with $2.4 \%$ critical stress level;

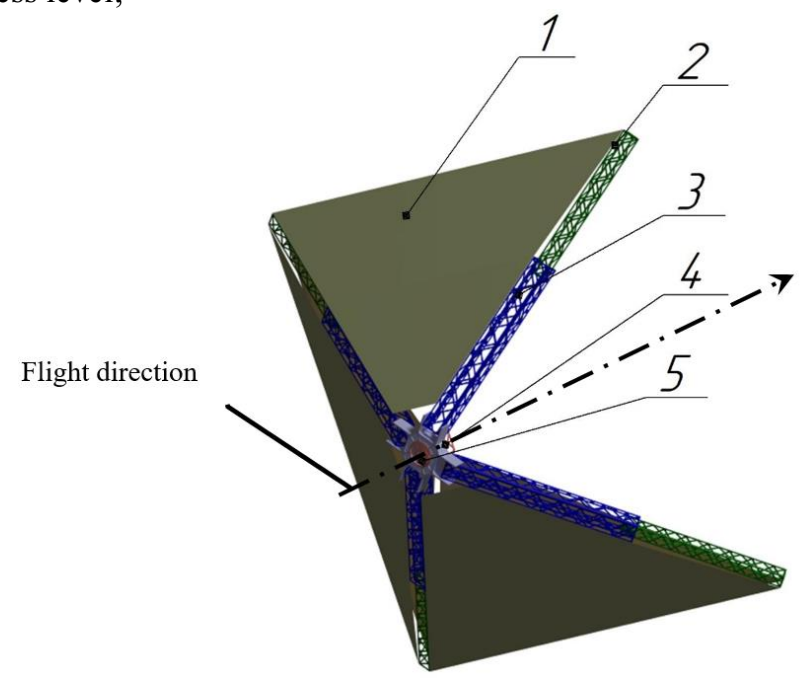

Fig. 1. Space debris catcher, one of the flaps not shown: 1 - debris catcher flap; 2, 3- webbed loadbearing element; 4 - base; 5 - mount.

\section{Results and discussion}

The temperature state of an expendable shell was modelled for a $400-\mathrm{km}$ orbit and $51.6^{\circ}$ inclination. The temperature variation dynamics on the outer and back surfaces of the multilayer shell was determined for the maximum value of direct solar radiation flux. It was established that the temperature on the external surface of the screen vacuum shield varied within a wide range: from $-98^{\circ} \mathrm{C}$ to $+84^{\circ} \mathrm{C}$. At the same time, the temperature of the meteoroid protection for the variously oriented parts of the trap stabilized almost 
completely after 30 days of orbital flight, and was at the level acceptable for the arimid fiber $\left(+11^{\circ} \mathrm{C}\right.$ to $-17^{\circ} \mathrm{C}$ ) (Fig. 2). This result confirms that the $10 \mathrm{~mm}$ thickness is sufficient for the outer layer of the screen vacuum shield.

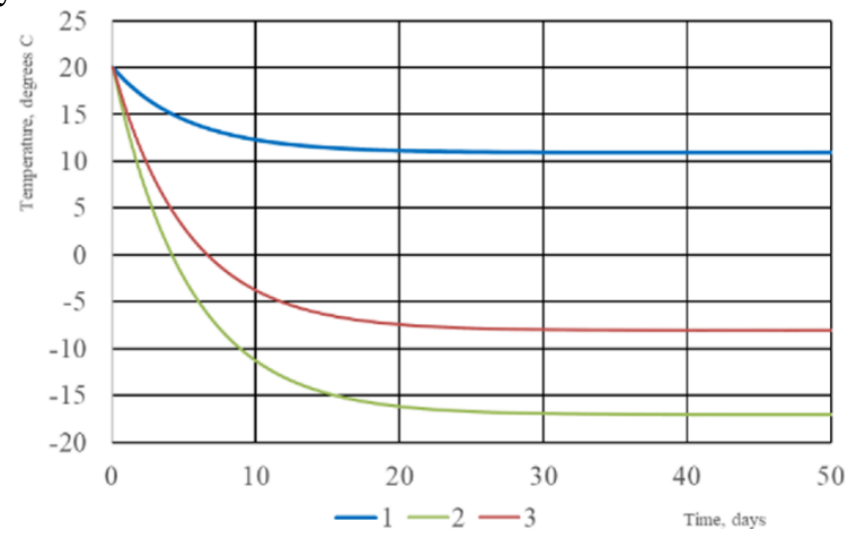

Fig. 2. Change in the temperature of the outer layer of the meteoroid protection for elements oriented towards the Earth (1), away from the Earth (2) and in the flight direction (3), as a function of time elapsed after launch, ${ }^{\circ} \mathrm{C}$.

To assess the stability of the multilayer flap wall/ shell, the consequences were analyzed for a high-speed impact at $90^{\circ}$ and at $45^{\circ}$ with an aluminum or ice debris particle, 0.5 to 10 $\mathrm{mm}$ in diameter at $4000 \mathrm{~m} / \mathrm{s}-7000 \mathrm{~m} / \mathrm{s}$. As seen in Fig. 3, at the moment of penetration, local temperature rises abruptly to about $500 \mathrm{~K}$, which points to the significance of the thermal stability of the materials used.

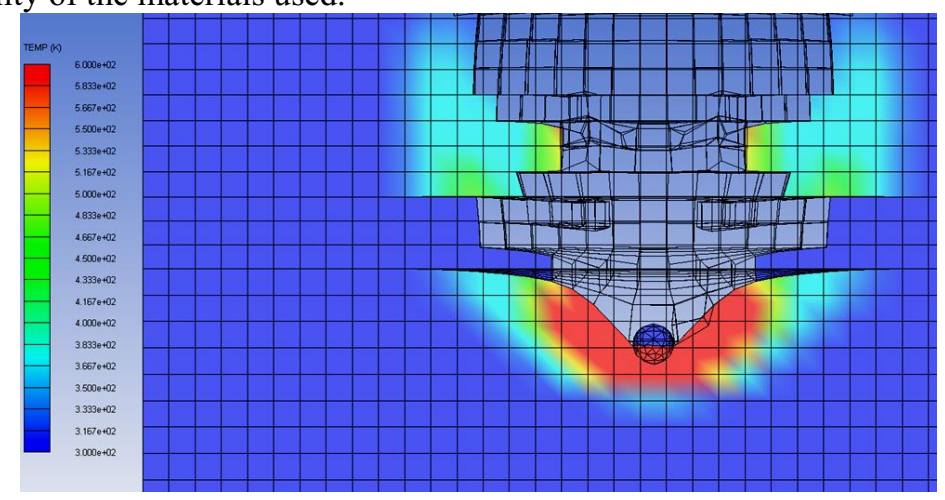

Fig. 3. The temperature distribution in an element of the multilayer structure at a high-velocity impact $(5000 \mathrm{~m} / \mathrm{s})$ of an aluminum particle, $1 \mathrm{~mm}$ in diameter (cross-section shows the impact center), $\mathrm{K}$.

Parametric modeling established that for a high-speed impact of a $1 \mathrm{~mm}$ aluminum particle at $5000 \mathrm{~m} / \mathrm{s}$ at $90^{\circ}$ to the surface, the instantaneous compaction, penetration and local compression of the first screen vacuum layers stack results in a noticeable extrusion of the destroyed material, as well as the propagation of the stress wave in the material. Then the particle penetrates the arimid layers and perforates them, forming numerous layer separation areas. Some of the patricle's kinetic energy converts into the elastic stretching and tearing of the arimid layers (threads). The residual kinetic energy of the particle and the accelerated part of the arimid layers is sufficient for the total deformation and failure of the second stack of the screen vacuum shield layers. The particle is partially destroyed in the second stack of arimid layers, with the fragments penetrating the stack. The characteristic size of the failure zone for the first arimid stack is $2.26 \mathrm{~mm}$. 


\section{Conclusion}

The proposed multilayer structure design can provide protection against ice debris particles up to $2 \mathrm{~mm}$ in diameter at up to $5000 \mathrm{~m} / \mathrm{s}$ impact velocity and against aluminum debris particles up to $1 \mathrm{~mm}$ in diameter at up to $4.500 \mathrm{~m} / \mathrm{s}$ impact velocity.

In our country there is a fairly large practical experience in the design, production and testing of large-size space structures, allowing to take into account the features of the thermal regime in the implementation of the project of the transformable space debris catcher [9-14].

Certain results of this research were obtained with funding from Ministry of Education and Science of Russian Federation within the incentive 1.2 of the federal targeted programme "R\&D in priority development areas of Russian science and technology sector in 2014-2020" (Agreement for grant N 14.574.21.0146 from September $26^{\text {th }}, 2017$, the unique identifier for the project RFMEFI57417X0146).

\section{References}

1. K. J. Kennedy, J. Raboin, G. Spexarth, G. Valle, Inflatable Structures Technology Handbook. Chapter 21; Inflatable Habitats JSC-CN-6300 (NASA, Johnson Space Center, 2000)

2. BEAM Fact Sheet: Demonstrating Technologies For Deep Space Habitation. URL: https://www.nasa.gov/sites/default/files/atoms/files/2016-march-beam-factsheet508.pdf (Accessed 01.03.2018)

3. R. T. Joyce, L. D. Carpenter, J.-M. Chang, D. L. Akin, 47-th Int. Conf. on Environmental Systems (2017)

4. J. Hinkle, R. Timmers, A. Dixit, J. Lin, J. Watson, 50-th AIAA/ASME/ASCE/AHS/ASC Structures, Structural Dynamics, and Materials Conference (2009)

5. I. I. Khamits, I. M. Filippov, L. S. Burylov, Kosmicheskaya tekhnika i tekhnologii 2 , 23 (2016) [in Russian]

6. N. A. Goldenko, Ye. P. Buslov, V. A. Fel'dshteyn, Proceed. of Mechanics and Mathematical Modelling in Engineering Conf. ded. to the $100^{\text {th }}$ anniv. of $V$. I. Feodos'yev (2016) [in Russian]

7. B. Lyndon, Handbook for Designing MMOD Protection (NASA, Texas, 2009)

8. W. Ley, K. Wittmann, W. Hallmann, Handbook of Space Technology (John Wiley \& Sons, Manhattan, 2009)

9. S. V. Reznik Materials and coatings in extreme conditions. View in the Future (Bauman MSTU Publ. House, Moscow, 2002)

10. V.A. Zavoruev, L.A. Kudryavin, V. I. Khalimanovich, Technical textiles 16 (2007)

11. L. V. Denisova, D.Yu. Kalinin, S. V. Reznik, Herald of the Bauman MSTU. Ser. Natures'. Science, 1 (82) (2011)

12. S. Reznik, Proc. 1-st Int. Workshop on Advanced Composite Materials and Technologies for Aerospace Applications (Wrexham, UK, 2011)

13. S. V. Reznik, O. V. Denisov, P. V. Prosuntsov, V. P. Timoshenko, and A. V. Shulyakovskii, Polymer Sci. 6, 3 (2013)

14. S. V. Reznik, P. V. Prosuntsov, K. V. Mikhailovsky, I. R. Shafikova, IOP Conf. 153 (2016) 012001 doi:10.1088/1757-899X/153/1/012001 